\title{
AIDS And The Funeral Industry In Southeastern Africa
}

David J. Snyder, (Email: snyder@ canisius.edu), Canisius College

Laurie Butler, (Email: butler@canisius.edu), Canisius College

Karen Goff, (Email: goff@canisius.edu), Canisius College

\begin{abstract}
This paper examines the impact of AIDS on the Funeral Industry in Southeastern Africa. It first presents an overview of AIDS in Southeastern Africa and then it delves into an examination of family funeral customs in select countries and how they have been affected by the AIDS epidemic. These countries include: Zimbabwe, Malawi, Zambia, South Africa, Botswana, and Uganda. Next, this paper takes a look at the impact of AIDS on hospital mortuaries in Zimbabwe. This is followed by an examination of the rise in the number of orphans along with the effect of AIDS on the classroom setting. Finally, four suggestions for fighting the disease are presented.
\end{abstract}

\section{INTRODUCTION}

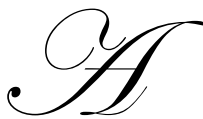

IDS has been a major problem in Africa for several decades. Numerous articles have listed statistics that have tracked the increase in HIV infections rates, cumulative AIDS cases, cumulative AIDS deaths, annual deaths to persons aged 15 to 49 (with and without AIDS), and AIDS death rates (Brisco 1999; Dowell 2000; O'Reilly 2001). Numerous articles have also discussed the background to AIDS (ie., the HIV/AIDS pyramid, current estimates of AIDS prevalence, transmission mechanisms, incubation period, and agegender distribution of reported AIDS cases) (National AIDS Coordination Programme 1998), the social and economic impact of AIDS (ie., orphans as a result of AIDS, population size and growth, child survival, new adult cases of tuberculosis as a result of AIDS, cost of health care, economic impacts b industry, and women and AIDS)(Bartholet, 2000; Masland and Nordland, 2000; Cowley, 2000)), and intervention to control the spread of AIDS (ie., knowledge of AIDS and interventions, prevention, the national AIDS coordination program, suggestions as to what needs to be done, and suggestions as to where we need to go from here). (Whitelaw, 2000; Wadman 2000; Whitelaw, 2001; Walt, 2001). One topic that has not been addressed in such detail is the impact of AIDS on families and the funeral industry when a family member succumbs to AIDS. (McNeil, Jr., 1998; Mdzungairi, 1999). This article will focus on the impact of AIDS on families and the funeral industry in several countries in southeastern Africa, with the primary focus being on Zimbabwe.

\section{AIDS EPIDEMIC HOT ZONE}

The AIDS epidemic is highest in the 29 countries of sub-Saharan Africa. In these countries, women's infections rates are often as high as men's and, when they die, orphans are frequently left behind. The African countries with the highest infection rates for adults (15 - 49) are Zimbabwe (26\%), Botswana (25\%), Namibia (20\%), Zambia (19\%), Malawi (15\%), Mozambique (14\%), Rwanda (13\%), and South Africa (13\%). All but Rwanda are in Southeastern Africa (Bartholet 200). This has cut deeply into the life expectancy of these nations. For example, the life expectancies with and without AIDS are as follows: Zimbabwe (41/66), Botswana (41/70), Namibia (41/64), Zambia (42/60), Malawi (40/53), Mozambique (38/53), and South Africa (47/64). All of these figures are for the period 2000 - 2005 (World Health Organization 1999). In less than a decade, the hard earned life expectancy gains in southeastern Africa have been wiped out. 


\section{AIDS EPIDEMIC IN ZIMBABWE}

As shown above, Zimbabwe has the highest infection rate. The country itself is roughly the size of California with a population of 12 million. In a country this size, it is projected that cumulative HIV infections will grow from 200,000 in 1985 to 500,000 in 1990, to 1,4000,000 in 1995 to 1,800,000 in 2000 to 2,000,000 in 2005. This is a ten-fold increase in twenty years! It is projected that cumulative AIDS cases will grow from 50 in 1985 to 20,000 in 1990 , to 180,000 in 1995 , to 650,000 in 2000 , to over $1,300,000$ in 2005 . Once again, an astronomical increase. This rise in the number of AS cases means that there will be a heavy burden on the health care system which is already under severe strain. The death toll will also be heart-wrenching. It is projected that cumulative AIDS deaths will rise from 100,000 in 1995 to 500,000 in 2000 to $1,200,000$ in 2005 . This represents an additional $1,100,000$ deaths in a ten year period. The death rate will increase in most age groups, but it will hit especially hard those who are in the prime working ages of 15 to 49. Without AIDS, due to economic progress, the annual death rate for this age category would have remained around 20,000 per year from 1990 to 2005 . With AIDS, the annual death rate for this age category will rapidly rise from 20,000 per year in 1990 to 170,000 per year in 2005 . This will have serious repercussions for the economic and social development of the country (NACP 1998). The central Statistical Office of Zimbabwe estimates that the annual number of deaths per 1,000 people will rise from approximately ten in 1993 to 23 by 2005. Without AIDS, the Central Statistical Office predicts that the death rate would have continued to decline (Central Statistical Office 1995).

\section{FAMILY FUNERAL CUSTOMS}

Funeral rituals typically take on much more importance in African society than they do in the West. Even the poorest laborer will have one investment, which is in a burial society. He will make monthly payments to this society to ensure that members of his family will be able to provide him with a formal burial, complete with flowers, coffin, and a full meal for the mourning relatives. With a soaring death rate, burial societies have had to dramatically increase both their joining fee and their monthly fees. And, to prevent people from joining just before their death, many burial societies have even introduced a waiting period for as long as one year before they will pay for the cost of the funeral. This has added to the financial burden of the laborer who oftentimes earns less than one dollar per day (McNeil, Jr., 1998).

African funeral rituals vary, but they usually involve washing the body, setting it out for public viewing, paying for a formal burial service, hosting an enormous banquet for mourners, and providing food and lodging for friends and relatives while they remain in mourning at your home for up to a week. And, it isn't uncommon for mourners to demand bus fare both to and from the funeral! For these reasons and others, funerals have become dramatically shorter, as the cost for a traditional funeral skyrockets.

According to the United Nations (1998), there are 5,500 AIDS related funerals in Africa every day. In a continent where death is a communal rather than a private matter, poverty and emotional exhaustion have taken their toll. The poorest go un-shrouded. Thousands of graves are left without markers, and people from all backgrounds admit that they no longer have the money or energy to mourn as they feel tradition demands (McNeil, Jr., 1998). This is evident in country after country in southeastern Africa.

\section{Zimbabwe}

Mr. Sibanda died in Bulawayo at the Mpilo Hospital. At the age of 40, he was the fourth in his family to die of aids in little over a year. Being illiterate, he, his wife and five children made to by selling vegetables and fish. His few cows had to be sold to pay for the funeral of his father and two brothers. Now, with his death, the family cannot even afford the $\$ 46$ to get his body out of the morgue and into the city cemetery. If his body is unclaimed, the hospital will be forced to cremate him which, according to the local ward councilor, is "taboo in African culture" (McNeil, Jr., 1998). More than 1,000 unclaimed bodes are given pauper funerals by the State each month as many families break tradition and take no steps to organize their relatives' burial (Mdzungairi 1999). 


\section{Zambia}

Dr. Rachel Baggaley, a World Health Organization AIDS specialist, says that big funeral have become completely overwhelming for farm workers. In Zambia, relatives would traditionally provide food, beverage and charcoal (for cooking and heating) to mourners. The cost was often a full month's wages. She realized how bad the situation had become when farmers started refusing farms workers leave for funerals. The workers were actually relieved that they were thus excused from having to provide a traditional funeral for the deceased (McNeil, Jr., 1998).

\section{South Africa}

Funerals were always public events in South Africa, where thousands turned out to pay their respect to young men and women killed by police in the struggle against white rule. Now, the major cause of death of adults is AIDS. It is not unusual for a person to attend several funerals in a single day. With the average cost of a funeral being $\$ 1,000$, this is quite a hardship on relatives since this is approximately one third of yearly per capita income. Mr. Moremi's family recently rented a tent and chairs, provided two large buses for transportation, and slaughtered a sheep to feed guests. With mourners typically staying for up to a week, the cost for food and heating fuel adds up quickly (Singer 2001).

\section{Malawi}

Jean Ngwira of a United Nations project for HIV - infected people in Malawi says that "Customarily, if my brother dies, my uncles, cousins and grandmother used to come over and sleep at my house for a week to console me and keep me company. Now, they only stay for a day or so." (McNeil, Jr., 1998).

\section{Uganda}

Among the Ganda in Uganda, mourners would traditionally bring a piece of brown cloth made from the bark of the mutuba tree, to help wrap the body. Since so few artisans know how to make it, the cost has shot up ten-fold from the pre-epidemic price (McNeil, Jr., 1998)

\section{Botswana}

Traditionally, most Africans would like to be buried in their home villages, but today that is almost impossible. It is expensive to find a refrigerated truck willing to carry the body, so relatives are forced to hire long distance taxis to transport the AIDS victims while they are still alive. This often causes a problem with other passengers who refuse to travel in a minivan with and incontinent and, sometimes, tubercular invalid (McNeil, Jr., 1998).

\section{IMPACT OF ZIMBABWE HOSPITALS}

As stated earlier, more than 1,000 unclaimed bodies are given pauper funerals in Zimbabwe each month. Mortuaries at these hospitals are unable to cope with the rising number of bodies. Up to three bodies are piles into trays meant for one, and those seeking to identify their dead often have to shuffle other bodies before they can retrieve the bodies of their relatives. A health official said that it was unusual to "trample upon the rights of the dead, but due to the rise in the cost of dying, relatives just disappear into thin air." (Mdzungairi, 1999).

The major cities in Zimbabwe are Harare (the capital), Bulawayo, Chinhoyi, Mutare, and Gweru. Interviews with hospital authorities in these cities revealed that most mortuaries are filled to overflowing, with an increasing number of corpses receiving pauper burials. at Mutare Provincial Hospital, there are 325 unclaimed bodies which have been in the mortuary for the past four months. Sixteen are infants below the age of two, whose mothers have disappeared. At Parirenyatwa Hospital, the country's larges referral hospital, in Harare, a mortuary designed to carry 42 bodies now accommodates 200 bodies at any given time. At least 58 bodies were given pauper burials last month after relatives failed to claim them for over 21 days. In many mortuaries, the cooling system no longer works 
properly, so the bodies give off a terrible stench, which affects the health of the hospital workers. Chinhoyi Provincial Hospital has a mortuary with a capacity for 24 bodies, but at any given time there are around 30 (Mdzungairi 1999).

\title{
ORPHANS
}

The number of orphans is on the rise in southeastern Africa as one or both parents contract AIDS and die. In 1998, the countries in southeastern Africa with the most orphans included: Zimbabwe $(360,000)$, Zambia $(360,000)$, Malawi (270,000), South Africa (180,000), and Mozambique (150,000) (Bartholet 2000). By the end of 2000, subSaharan Africa will have 10.4 million children under the age of fifteen who have lost their mothers or both parents (Masland and Nordland 2000). The number is expected to double or triple by 2010. A generation of orphans will undermine economic development in these countries since orphans can seldom afford education. Most orphans are taken in by extended families, but the huge number of orphans fills orphanages, too. Compared with children with parents, AIDS orphans are at a far greater risk of malnutrition and of not receiving the healthcare that they need (Masland and Nordland 2000).

\section{ORPHANS IN ZIMBABWE}

The number of orphans in Zimbabwe has grown from a small number in 1990to 150,000 in 199a5, to 550,000 in 2000 and a projected 900,000 in 2005 (NACP 1998). This will cause an enormous strain on the social system to be able to cope with such a large number of orphans and to be able to provide them with the needed care and support. At the family level, there will be an increased burden on the extended family which has traditionally been responsible for caring for orphans. Often, it will be the grandparents who will be left to care for the children or it will be the oldest son or daughter who will suddenly become the head of the household with the primary responsibility for caring for younger siblings. At the community and national level, there will be an increased burden on society to provide services for these children, including orphanages, health care and schooling. Those children who do not receive adequate health care and schooling will cause an increasing burden on society in later years. Many may turn to crime or prostitution to provide form themselves.

\begin{abstract}
AIDS IN THE CLASSROOM
Southeastern Africa is losing teachers and students, and with them its hope for the future. By some estimates, as many as a third of the teachers may be HIV positive in South Africa, which is a higher infection rate than the general population. In Zambia, two teachers are dying for every one that graduates from a training school. In Swaziland, the AIDS toll has reduced the teacher to student ratios to levels not seen since the 1970's (Whitelaw 2000). Some of the educational investment in today's children has already been lost as students become infected at startling rates as well. About half of those newly infected with AIDS are younger than 25. One survey at the University of Durban - Westville estimated that one third of its students are HIV positive (Lovgren 2000). Educators complain that many students refuse to wear condoms or to receive counseling.
\end{abstract}

\section{FIGHTING THE DISEASE}

President Daniel rap Moi of Kenya has urged his fellow citizens to abstain from sex for at least two years to try to curb the spread of AIDS. His government has also announced plans to import 300 million condoms to fight AIDS, drawing criticism from religious leaders. Recently Moi called for the death penalty for people who knowingly infect others with HIV/AIDS, to deter men from passing the disease to younger women (Reuters 2001).

What are more realistic actions that can be taken to slow the spread of the contagion? Cowley (2000) has four primary suggestions. The first one is to break the silence. Until recently, few African leaders acknowledged that AIDS was a problem. Swaziland, Botswana, and Namibia have announced new anti-AIDS initiatives this past year as they team up with corporations and community groups to raise public awareness. The second suggestion is to promote safer sex. The most successful prevention efforts have aimed not just to inform people but to change social norms. Still, condom use is rare. A Zambian survey found that only $6 \%$ of people reported using a condom in their last encounter with a spouse or live-in partner (O’Reilly 2001). Many Africans know that unprotected sex leads to 
AIDS, but they don't change their behavior. The third suggestion is to target women. Unfortunately, African women have little say in condom use and their powerlessness is costing them dearly. Teenage girls have five times the infections rate of boys because older men prey on them. AIDS can have a serious on the lives of women if it strikes a family member. In many cases, women do not have a secure occupation that can provide a steady income. And, they may not even have the rights of inheritance. Thus, if the husband dies, the surviving wife and children may be extremely vulnerable and subject to exploitation (NACP 1998). The final suggestion is to develop a vaccine. The AIDS war is heating up (Walt 2001). The major pharmaceuticals companies were taken by surprise when Cipla, a small Bombay drug company, offered to sell its AIDS drugs to poor countries at $90 \%$ less than competitors charge. Bristol-Myers Squibb and Merck cut prices throughout the developing world, a move that will benefit victims in Africa (Whitelaw 2001). Still, an actual AIDS vaccine is still far away. Most scientists say there is almost no chance that they will have a vaccine in hand by President Clinton's 2007 deadline (Waldman 2001).

\section{CONCLUSION}

AIDS has had a major impact on many sectors of society in southeastern Africa. One area that has been little studied is the impact of AIDS on the funeral industry in Africa. What scant research there is shows that traditional African funeral customs are being discarded as people become overwhelmed with the financial and emotional burdens of so many deaths. Much of this research on the families involved in AIDS deaths is anecdotal. It has also been shown that hospital mortuaries are becoming overwhelmed as bodies outnumber spaces for bodies. And, as more bodies lie unclaimed as families refuse to collect them due to the resulting financial burden, the governments in these southeastern countries are forced to divert scarce resources toward providing for pauper burials.

\section{SUGGESTIONS FOR FUTURE RESEARCH}

Future research should systematically examine how funeral customs are changing country by country in southeastern Africa. Which customs are being maintained? Which ones are being dropped? What new customs are evolving? It would also be useful to research how hospitals are dealing with the crisis of increasing numbers of bodies in their mortuaries and how the governments are dealing with the rise of pauper burials, for which they must pay. What actions, if any, can the governments take to make funerals more affordable in this age of AIDS, so that people will be willing to claim the bodies of their deceased relatives? Last of all, research needs to be conducted on African burial societies to see how they are coping with rapid changes these past couple of decades. Ethnographic research methodologies would be quite useful here, as relatives of the deceased, government and hospital officials, and burial society owners are both observed and interviewed.

\section{REFERENCES}

1. $\quad$ Bartholet, Jeffery, The Plague Years, Newsweek, pp. 33 - 37, January 17, 2000.

2. Central Statistical Office and Macro International, Inc. Zimbabwe Demographic and Health Survey 1994, Harare: Central Statistical Office and Calverton, Maryland: Macro International Inc., 1995.

3. Cowley, Geoffrey, Fighting the Disease: What Can Be Done, Newsweek, P. 38, January 17, 2000.

4. Forgy, Larry, The Economic Impact of AIDS in Zimbabwe: Economic Analysis for AIDS Project Paper, REDSO/ESA, January, 1993

5. Hanson, K, AIDS: What Does Economics Have to Offer? Health Policy and Planning, 7(4) pp.315-328, 1992.

6. Masland, Tom and Rod Nordland, 10 Million Orphans, Newsweek, pp. 42 - 45, January 17, 2000.

7. McNeil, Jr., Donald G., AIDS Takes a Toll on Africa, Even After Death, The New York Times, pp. A10, A18, December 16, 1998.

8. Mdzungairi, Wisdon, Over 1,000 Given Pauper's Burial Monthly, Zimbabwe Independent, October 30, November 5, 1998.

9. National AIDS Coordination Program, Ministry of Health and Child Welfare. Report on HIV, AIDS, and STD Surveillance Workshop: 23 - 26, February, 1997

10. Over, Mead and Martha Ainsworth, Coping with AIDS: The Economic Impact of Adult Mortality from AIDS and Other Causes on Households in Kagera, Tanzinia, World Bank, 1996 
11. O'Reilly, Brian, Death of a Continent, Fortune, pp. 1 - 9, November 13, 2000.

12. Republic of Zimbabwe, Second Medium Term Plan (MTP2) for the Prevention, Control and care of HIV/AIDS/STD, 1994-1998.

13. Reuters, Kenyans Urged to Skip Sex for Two Years, pp. 1-3, www.msnbc.com/news/599432.asp, July 12, 2001

14. Reuters, New African Union Races Against Time, pp. 1 - 5, www.msnbc.com/news/599311.asp, July 12, 2001

15. Roberts, Matthew and Bill Rau, African Workplace Profiles: Private Sector AIDS Policy, AIDSCAP, Arlington, VA.

16. Wadman, Meredith, How Close is the AIDS Vaccine?, Fortune, pp. 1 - 3, November 13, 2000.

17. Walt, Vivienne, AIDS Drug War Heats Up, Fortune, pp. - 2, June 25, 2001

18. Whitelaw, Kevin, AIDS in the Classroom, U.S. News and World Report, pp. 32 - 33, February 14, 2000.

19. Whitelaw, Kevin, Just the Medicine: Cheaper AIDS Drugs, U.S. News and World Report, pp. 1 - 2, www.usnews,com/usnews/issue/010326/aids, March 26, 2001.

20. Whiteside, Alan and Greg Wood, Socio-Economic Impact of HIV / AIDS in Swaziland, Capricorn Africa Economic Associates, Mbabane, 1994

21. Whiteside, Alan and John Stover, The Demographic and Economic Impact of AIDS in Africa, AIDS 1997, 11 (supplement B): S55 - S61.

22. World Bank, Confronting AIDS: Public Priorities in a Global Epidemic, New York: Oxford University Press, 1997.

\section{NOTES}

